\title{
Fulminant guillain barré syndrome (GBS) refractory to intravenous immunoglobulin (IVIG) treated with therapeutic plasma exchange
}

\begin{abstract}
A 53year old man was brought to the Neurology Intensive Care Unit, on a ventilator with a Glasgow Coma Scale (GCS) of 5T (E-Eye opening, V-Verbal response, M-Motor response, T-Intubated- $\left.\mathrm{E}_{4} \mathrm{~V}_{\mathrm{T}} \mathrm{M}_{1}\right)$ which later worsened to $2 \mathrm{~T}\left(\mathrm{E}_{1} \mathrm{~V}_{\mathrm{T}} \mathrm{M}_{1}\right)$. On detailed evaluation, a diagnosis of Fulminant Guillain Barré Syndrome (Hughes score 5) was made and Intravenous Immunoglobulin (IVIG) was instituted. No response was noted even seven days after IVIG administration. Plasma exchange was initiated. A total of 14 exchanges were performed over a period of 13 weeks wherein 21.8 liter of plasma was exchanged. Patient started showing signs of improvement by the 6th week of illness. By the $19^{\text {th }}$ week of illness, he could be completely weaned off the ventilator. At the time of discharge $\left(27^{\text {th }}\right.$ week of illness), the power in his upper limbs was 4 and 2 in his lower limbs. Hughes score was 4 and GCS was $15\left(\mathrm{E}_{4} \mathrm{~V}_{5} \mathrm{M}_{6}\right)$. This case illustrates the significant role of plasma exchange in the management of Fulminant Guillain Barré Syndrome.
\end{abstract}

Keywords: fulminant guillain barré syndrome, plasma exchange, neuromuscular paralysis, gangliosides, peripheral nerves
Volume 5 Issue 3 - 2017

\author{
Nair Revathy,' Raina Abhinav, ${ }^{2}$ Nair \\ Muralidharan, ${ }^{2}$ Gupta Debasish' \\ 'Department of Transfusion Medicine, Sree Chitra Tirunal \\ Institute for Medical Sciences and Technology, India \\ ${ }^{2}$ Department of Neurology, Sree Chitra Tirunal Institute for \\ Medical Sciences and Technology, India
}

\begin{abstract}
Correspondence: Dr. Debasish Gupta, Professor, Department of Transfusion Medicine, Sree Chitra Tirunal Institute for Medical Sciences and Technology, Trivandrum 6950I7, India, Tel 047I-
\end{abstract} 2524I77,902012010,Email debasishgupta@gmail.com

Received: August 16, 2017 | Published: October 12, 2017
Abbreviations: ASFA, american society for apheresis; CMAPs, compound muscle action potentials; CSF, cerebrospinal fluid; EEG, electroencephalogram; EMG, electromyogram; EVM, eye opening, verbal response, motor response; GBS, guillain barré syndrome; GCS, glasgow coma scale; IVIG, intravenous immunoglobulin; NCS, nerve conduction study; NMICU, neuro-medical intensive care unit; NSTEMI, non ST segment elevation myocardial infarction; SNAPs, sensory nerve action potentials

\section{Introduction}

Guillain-Barré Syndrome (GBS) is an important cause of acute neuromuscular paralysis characterized by acute areflexic paralysis with albumin-cytological dissociation (i.e. high levels of protein in the cerebrospinal fluid and normal cell counts). Molecular mimicry and a cross-reactive immune response play a crucial role in its pathogenesis, at least in those cases with a previous Campylobacter jejuni infection and with antibodies to gangliosides. ${ }^{1}$ Guillain-Barre Syndrome is currently the most frequent cause of acute flaccid paralysis worldwide and constitutes one of the serious emergencies in neurology. ${ }^{2} \mathrm{We}$ report our observation in a patient who presented in a state mimicking cerebral death. The patient's efferent nerves were completely affected and he developed Fulminant GBS with inexcitable peripheral nerves.

\section{Case presentation}

A 53 year old, Type II diabetic and hypertensive gentleman was admitted in the Neuro Medical Intensive Care Unit (NMICU) following a rapidly progressive, acute ascending paralysis of all four limbs with dysphagia and regurgitation. He underwent intubation for acute respiratory distress at a local hospital and was shifted to our centre on the fifth day post intubation. No sedative drug had been administered. On examination, vital signs were stable. Patient was conscious, obeying and comprehending commands. Glasgow Coma
Scale (GCS) at admission was $\mathrm{E}_{4} \mathrm{~V}_{\mathrm{T}} \mathrm{M}_{1}$ (E-Eye opening, V-Verbal response, M-Motor response, T-Intubated). ${ }^{3} \mathrm{He}$ was noted to have ophthalmoparesis with bilateral ptosis. Pupils were bilaterally $4 \mathrm{~mm}$, sluggishly reactive to light. In addition, he had bifacial paresis with flaccid, areflexic quadriplegia. Nerve Conduction Study (NCS) showed ineluctable Compound Muscle Action Potentials (CMAPs) from bilateral peroneal, tibial, median and ulnar nerves. F waves and Sensory Nerve Action Potentials (SNAPs) were also absent from bilateral upper and lower limb nerves. GM1 antibody was borderline positive. Rest of the antiganglioside antibody profile including anti GQ1b was negative. Intra Venous Immunoglobulin (IVIG) was initiated at the local hospital since GBS was suspected and the course was completed at our centre. The reports of the haematological investigations done are as follows: Hemoglobin: 10.7g/dL, Total Count: 13,900/cumm, Serum Albumin: 4.2g\%, Serum gamma globulins: Elevated, INR: 1.2, Serum Creatinine: $0.57 \mathrm{mg}$ / $\mathrm{dL}$, Serum Calcium: $8.9 \mathrm{mEq} / \mathrm{L}$, Sodium: $136 \mathrm{mEq} / \mathrm{L}$, Potassium: $3.8 \mathrm{mEq} / \mathrm{L}$, Hepatitis A $(\operatorname{IgM}) / \mathrm{HIV} / \mathrm{HBsAg} / \mathrm{HCV}$ : Negative Within 3 days of admission, patient developed complete ophthalmoplegia with fixed dilated pupils. Vestibulo-ocular reflexes were also absent and Electroencephalogram (EEG) showed generalised delta range slowing with occasional sleep spindles. There was no reactivity to noxious/visual stimulus. GCS worsened to $\mathrm{E}_{1} \mathrm{~V}_{\mathrm{T}} \mathrm{M}_{1}$. The possibility of central demyelination in addition to peripheral demyelination consistent with Bickerstaff encephalitis with Guillain Barré Syndrome overlap was considered. MRI performed on the $5^{\text {th }}$ day of admission to rule out mesencephalic/diencephalic pathology was found to be normal. Cerebrospinal Fluid (CSF) analysis performed 2weeks after onset of symptoms showed a sterile CSF with albumino-cytological dissociation. Needle electromyogram performed on the $4^{\text {th }}$ week of admission showed evidence of denervation from all sampled muscles. Since the patient had worsening despite initiating IVIG, it was decided to switch over to plasma exchange (1week post last IVIG dose). 
He received a total of 14 Plasma exchanges. His body weight was $80 \mathrm{Kg}$ and plasma volume was calculated as 3.48 litre (Total Plasma Volume=Total Blood Volume (1-Hematocrit)). 6.82 litre of plasma were exchanged over 4days (alternate days) by the intermittent type of apheresis machine. In each session only less than half the plasma volume was exchanged in view of autonomic instability. Further exchanges had to be avoided for the next 3 weeks as there were frequent episodes of hypotension and bradycardia. NCS repeated after 1 month of illness showed the same result.

By the $6^{\text {th }}$ week of hospitalisation, the patient started responding to painful stimulus by moving his head. After stabilisation of hemodynamic parameters, 4 exchanges were performed, wherein 6.26 litre of plasma were exchanged. All the 4 were of the intermittent variety. By the $10^{\text {th }}$ week of hospitalisation, there was partial opening of eyes to commands and flexion of interphalangeal joints of both upper limbs. The GCS improved to $\mathrm{E}_{4} \mathrm{~V}_{\mathrm{T}} \mathrm{M}_{6} .6$ more sessions of plasma exchange were performed, of which 5 were continuous apheresis. Hypotension was experienced in two such continuous exchanges and the procedure had to be discontinued. 8.7 litre plasma was exchanged at the end of 6 exchanges. The type of plasma exchange performed depended on the availability of the kits. The details of the plasma exchanges have been enlisted in Table 1. On the $19^{\text {th }}$ week of hospitalisation, he could be weaned off the ventilator support. On the $25^{\text {th }}$ week, the tracheostomy tube was changed to speaking tracheostomy tube following which he could vocalise.

His course in the hospital was complicated by 2 episodes of cardiac arrest, probably related to autonomic dysfunction. The ST-T wave changes noted were treated as Non-ST-Segment Myocardial Infarction (NSTEMI) as per attending Cardiologist. He had Ventilator Associated Pneumonia which was treated as per the antibiotic sensitivity report. At the time of discharge, the power in both upper limbs was $4 / 5$ and in lower limbs 2/5. The Hughes score was 4 and GCS $15\left(\mathrm{E}_{4} \mathrm{~V}_{5} \mathrm{M}_{6}\right)$. He was advised continued rehabilitation in a physiatry till such time that he would be able to walk. The neurological parameters are tabulated in Table 2.

Table I Details of the plasma exchanges performed

\begin{tabular}{lllll}
\hline S. No & $\begin{array}{l}\text { Type of plasma } \\
\text { exchange }\end{array}$ & $\begin{array}{l}\text { Volume of plasma } \\
\text { exchanged }(\mathbf{m L})\end{array}$ & $\begin{array}{l}\text { Plasma volumes } \\
\text { exchanged }\end{array}$ & Adverse reactions \\
\hline AI & Intermittent & 1407 & 0.4 & Nil \\
A2 & Intermittent & 1825 & 0.5 & Nil \\
A3 & Intermittent & 1700 & 0.48 & Hypotension \\
A4 & Intermittent & 1888 & 0.54 & Nil \\
B1 & Intermittent & 1070 & 0.3 & Nil \\
B2 & Intermittent & 1800 & 0.51 & Nil \\
B3 & Intermittent & 1890 & 0.54 & Nil \\
B4 & Continuous & 1500 & 0.43 & Nil \\
C1 & Continuous & 1000 & 0.28 & Hypotension \& Bradycardia \\
C2 & Continuous & 1600 & 0.45 & Nil \\
C3 & Continuous & 1200 & 0.34 & Nil \\
C4 & Continuous & 1900 & 0.54 & Nil \\
C5 & Continuous & 1300 & 0.37 & Hypotension \\
C6 & Intermittent & 1706 & 0.48 & Nil \\
Total & & 21,786 & & \\
\hline
\end{tabular}

14 plasma exchanges were performed wherein 21.79 litre plasma were exchanged.
A. Exchanges in the $4^{\text {th }}$ week of illness
B. Exchanges in the $8^{\text {th }}$ week of illness
C. Exchanges in the $16^{\text {th }}$ and $17^{\text {th }}$ weeks of illness.

Table 2 Improvements in the neurological parameters ${ }^{3}$

\begin{tabular}{lllll}
\hline Neurological parameters & Day I & Day $\mathbf{3}$ & I0 $^{\text {th }}$ Week & $\mathbf{2 5}^{\text {th }}$ Week \\
\hline GCS & $\mathrm{E}_{4} \mathrm{~V}_{T} \mathrm{M}_{1}$ & $\mathrm{E}_{1} \mathrm{~V}_{T} \mathrm{M}_{1}$ & $\mathrm{E}_{4} \mathrm{~V}_{T} \mathrm{M}_{6}$ & $\mathrm{E}_{4} \mathrm{~V}_{5} \mathrm{M}_{6}$ \\
Hughes Score & 5 & 5 & 5 & 4 \\
\multirow{3}{*}{ Muscle Power } & $\mathrm{UL}-0 / 5$ & $\mathrm{UL}-0$ & $\mathrm{UL}-2$ & $\mathrm{UL}-4$ \\
& $\mathrm{LL}-0 / 5$ & $\mathrm{LL}-0$ & $\mathrm{LL}-0$ & $\mathrm{LL}-2$ \\
& & & & $\mathrm{Rt} \mathrm{AJ}+$ \\
Reflexes & Areflexia & Areflexia & Areflexia & Lt AJ + \\
& & & & Rt Plantar-F \\
& & & & Lt Plantar-F \\
\hline
\end{tabular}

UL, upper limb; LL, lower limb; Rt, right; Lt, left;AJ, ankle jerk; F, flexor

Citation: Revathy N,Abhinav R, Muralidharan N, et al. Fulminant guillain barré syndrome (GBS) refractory to intravenous immunoglobulin (IVIG) treated with therapeutic plasma exchange. Hematol Transfus Int J. 20I7;5(3):245-248. DOI: I0.15406/htij.20I7.05.00I20 


\section{Ethical clearance}

Ethical clearance was obtained from the Institutional Ethics Committee

\section{Discussion}

The diagnosis of GBS in our patient was based on a rapidly progressive ascending, flaccid, areflexic quadriparesis with albuminocytological dissociation and ineluctable CMAPs on NCS. Fulminant GBS is a rare entity. Only 20cases have been reported in the literature. The occurrence rate is higher for men than for women. ${ }^{4}$ Out of the 12cases reported by Vargas et al., ${ }^{4}$ albumino-cytological dissociation was found in 9 cases out of the 12. In the other three cases, cerebrospinal fluid was found to be normal or showed pleocytosis. Of the 12 cases, the therapeutic methods are described in only seven cases. Three patients died, two from cardiac arrest related to dysautonomia and one from a massive anterior myocardial infarction. Two patients showed poor recovery, with permanent disabling weakness. The others could walk with persistent minor problems. ${ }^{4-16}$ Our patient recovered with residual weakness in the lower limbs.

American Society for Apheresis (ASFA) classifies GBS under Category I, Grade 1A for therapeutic apheresis. Exchange of 1-1.5 plasma volumes for 5-7 procedures is recommended by ASFA for management of GBS but management of Fulminant GBS might not be feasible with the above dosage. The hemodynamic instability in the patients leads to early termination of the procedure thereby necessitating more number of procedures in total. GBS (Post IVIG) has been classified under Category III, Grade $2 \mathrm{C} .{ }^{17}$ Our patient, after a failure with IVIG (30g OD for 5 days), responded well to plasma exchange.

In a study by Hadden et al., ${ }^{18}$ the outcomes in response to plasma exchange or infusion of gamma globulin, or a combination of both treatments, did not differ. ${ }^{18}$ Chaves et al. ${ }^{1}$ reported a case of Fulminant Guillain Barré Syndrome who was treated first with 5days of IVIG $35 \mathrm{~g}$ / day, with no response. Thereafter, he received 6 plasma exchanges. IVIG was repeated for 5 more days, followed by slow and steady improvement 2 months later. Fulminant GBS has a poor recovery rate and a high mortality, particularly in relation to dysautonomia. Nerve inexcitability on EMG, the need for ventilatory support for more than 1 month and severe rapidly progressive are bad prognostic features. ${ }^{19}$ Our patient had two episodes of cardiac arrest owing to dysautonomia from which he was successfully revived. Susuki et al. ${ }^{20}$ mentions that Axonal forms of GBS with positive Anti GM1 ganglioside antibodies respond well to a combination of Intravenous methyl prednisolone and IVIG $^{20}$ but our patient (Anti GM1 borderline positive) responded to intensive plasma exchange.

\section{Conclusion}

Guillain-Barré Syndrome can, in rare cases, present with signs of coma and absent brainstem reflexes. This is an important variant of GBS to be considered, because it is potentially easy to make a misdiagnosis without proper evaluation and the potential consequences would be disastrous. ${ }^{4}$ It is essential to conduct electrophysiological tests, laboratory and imaging studies in patients with suspected brain death where a cause is not clearly determined. After evaluation, our patient was refractory to IVIG but responded to intensive plasma exchange. We recommend plasma exchange in such a scenario albeit a requirement of large number of cycles. The diagnosis and management of Fulminant GBS is a challenge and we recommend a multidisciplinary approach comprising of Neurologists, Transfusion Medicine specialist and Anaesthesiologist.

\section{Acknowledgements}

The authors would like to express profuse gratitude to Mr. Subhash Baiju, Terumo BCT for training the NMICU staff and Transfusion Medicine residents in Continuous apheresis. We would also like to thank the Nursing staff of NMICU and the staff of Dept of Transfusion Medicine for their continuous support.

\section{Patient consent form}

As per the guidelines of Institutional Ethics Committee, the consent of every patient is taken prior to publication.

\section{Conflict of interest}

The author declares no conflict of interest.

\section{References}

1. Chaves SG, Aguiar TC, Câmara M, et al. Guillain-Barré Syndrome with absent brain stem reflexes: a case report. EJCRIM. 2014;1:167.

2. Yuki N, Hartung HP. Guillain-Barré Syndrome. $N$ Engl $J$ Med. 2012;366(24):2294-2304.

3. Buck Christensen. Glasgow Coma Scale Adult. Medscape, USA; 2014.

4. Vargas F, Hilbert G, Gruson D, et al. Fulminant Guillain-Barre syndrome mimicking cerebral death: case report and literature review. Intensive Care Med. 2000;26(5):623-627.

5. William M Carroll, Frank L Mastaglia. Locked-in coma in postinfective polyneuropathy. Arch Neurol. 1979;36(1):46-47.

6. Kotsoris H, Schliefer L, Menken M, et al. Total locked-in state resembling brain death in polyneuropathy. Ann Neurol. 1984;16(1):150.

7. Coad NR, Byrne AJ. Guillain Barre syndrome mimicking brainstem death. Anaesthesia. 1990;45(6):456-457.

8. Drury I, Westmoreland BF, Sharbrough FW. Fulminant demyelinating polyradiculoneuropathy resembling brain death. Electroencephalogr Clin Neurophysiol. 1987;67(1):42-43.

9. Hassan T, Mumford C. Guillain Barre Syndrome mistaken for brain stem death. Postgrad Med J. 191;67(785):280-281.

10. Fuller GN, Jacobs JM, Lewis PD, et al. Pseudoaxonal Guillain Barre syndrome: severe demyelination mimicking axonopathy. A case with pupillary involvement. $J$ Neurol Neurosurg Psychiatry. 1992;55(11):1079-1083.

11. Martí-Massó JF, Suárez J, López de Munain A, et al. Clinical signs of brain death simulated by Guillain-Barre Syndrome 1993. J Neurol Sci. 1993;120(1):115-117.

12. Tan AK, Chee MW. Fulminant Guillain-Barre Syndrome with quadriplegia and total paresis of motor cranial nerves as a result of segmental demyelination. J Neurol Sci. 1995;134(1-2):203-206.

13. Bohlega SA, Stigsby B, Haider A, et al. Guillain-Barre Syndrome with severe demyelination mimicking axonopathy. Muscle Nerve. 1997;20(4):514-516.

14. Hughes R, McGuire G. Neurologic disease and the determination of brain death: The importance of a diagnosis. Crit Care Med. 1997;25(11):19231924.

15. Berciano J, Figols J, García A, et al. Fulminant Guillain Barre Syndrome with universal inexcitability of peripheral nerves: a clinicopathological study. Muscle Nerve. 1997;20(7):846-857.

16. Bakshi N, Maselli RA, Gospe SM, et al. Fulminant demyelinating neuropathy mimicking cerebral death. Muscle Nerve. 1997;20(12):15951597. 
17. Schwartz J, Padmanabhan A, Aqui N, et al. Guidelines on the use of therapeutic apheresis in clinical practice-evidence-based approach from the writing committee of the american society for apheresis: the seventh special issue. J Clin Apher. 2016;31(3):149-162.

18. Hadden RD, Cornblath DR, Hughes RA, et al. Electrophysiological classification of guillain-barre syndrome: clinical associations and outcome. Plasma exchange/sandoglobulin guillain-barre syndrome trial group. Ann Neurol. 1998;44(5):780-788.
19. Winer JB, Hughes RAC, Greenwood RJ, et al. Prognosis in GuillainBarre Syndrome. Lancet. 1985;1:1202-1203.

20. Susuki K, Nobuhiro Yuki. Effect of methylprednisolone in patients with Guillain-Barré Syndrome. Lancet. 2004;363(9416):1236-1237. 